\title{
The Complexities of New Media: Can the 'Web Media' Completely Erase Traditional \\ Media from the Communication Industry?
}

\section{Ahmad Muhammad Auwal, Nasarawa State University, Nigeria}

\begin{abstract}
Over the years, there has been a popular outcry among investors and operators in the communication industry that the advent of new Information and Communication Technologies (ICTs) will affect the survival and mode of operation of the traditional media, especially newspapers and magazines. Although it is not in doubt that these technologies pose serious challenges to the survival of mainstream media. This has generated controversies as to whether the 'web media' will completely erase or overshadow the conventional media. This and other issues surrounding the convergence of new and mainstream media, is the thrust of this paper.
\end{abstract}

Keywords: Information and Communication Technologies, traditional media, Web media 


\section{Introduction}

It is not in doubt, that the advent of new media technologies poses great challenge to the survival of traditional media especially newspapers and magazines. The Information and Communication Technologies (ICTs) have impacted on the society in positive and negative dimensions. Auwal (2015a, p. 29) rightly explains this scenario when he writes that, "over the years, the transitional advancement in digital technologies and the increasing number of new media platforms have revolutionized the ways in which people communicate and share information. These technologies have affected the socio-cultural, political and economic structures of the contemporary society."He explains further that, new media emerged as powerful communication and development tools, adding to the potency of mobile telecommunications as drivers of economic and democratic change. New media technologies have significant impacts on organizational, professional and individual reputations.

The impacts, more often are evident in the journalism profession, especially in the print industry. According to Ezea, Ozibo and Hassan (2013), the world is changing fast and much of that change is driven by technology. This is no doubt, the power of Information and Communication Technologies (ICTs) of which the Internet plays a prominent role, not only in terms of the diffusions of innovations, but also in terms of their operations. The Internet is a dynamic tool wherein new changes occur almost by the day. In the same vein, Sambe (2014b, p. 140) state that, "we live in a changing world and one of the developments that brought about changes in modern world is information and communication technologies. One of the industries that have benefited from the impact of ICTs is the print media industry."Idiong (2012, p. 2) corroborates this view in the following words:

In no other profession are the effects of these changing times more keenly felt than in the journalism profession; no other professionals have to depend on the latest media technologies for their day-to-day tasks as much as journalists do. These new technologies, known in communication parlance as new media, have both complemented and complicated the traditional reportorial tools and tasks of the would-be journalist.

In a similar note, Esimokha (2011) explains that, technological advancement has drastically altered the practice of journalism profession as never before. The emergence of computer and 
its application to newsgathering, writing, editing, design, production and distribution has changed previous approaches which were hitherto manual. The development of the Internet and other Information and Communication Technologies (ICTs) innovations hastransformed the print media industry significantly. Nwabueze (2011, p. 89) argues that, "a print media establishment in contemporary society can hardly survive without new communication technologies such as computers, the Internet, satellite television for monitoring local and international news, among others.'This piece intends to find out how these technological innovations (new media) affect the operations and survival of print media industry in terms of newsgathering and processing, including production and management of newspapers and magazines. Paramount to this discussion is the need to make clarification on some key terms such as "traditional media" and "new media" as this will go a long way to facilitate better understanding of the topic of discussion.

\section{Mass Media: The Traditional (Conventional) Category}

The term "media" has been defined in different ways by experts and scholars in mass communication. In simple terms, mass media are organs (institutions or channels) of information dissemination to people at diverse locations. According to Asemah (2011, p. 18), "media are channels or technological devices through which messages are conveyed to a large and heterogeneous audience. They are the vehicles that are used for conveying messages from a source to a large destination." The author clarifies further that, "mass media are the devices for moving messages across distance or time to accomplish mass communication." Also, it is important to note thatthese channels (mass media) are broadly categorisedinto two groups. These include the print media, which consist of newspapers, magazines, books, journals and other documented means of information dissemination. The electronic media, which arealso divided into two groups, such asthe broadcast and the new or social mediaare made up of the second category of the mass media. Radio and television are the two channels that made up the broadcast media. The print and broadcast media are the categories of mass media often called the "traditional," "conventional" or "mainstream" media.On the other hand, the Internet and other electronic means of information dissemination that function with the aid of the Information and Communication Technologies (ICTs), such as GSM handsets and other mobile electronic gadgets, constitute the new or social media. In fact, the new or social media are characterized with the use of computer and the Internet. Oso (2007) cited in Nwabueze (2009) 
describes Internet as the most ubiquitous of the new media. The Internet and the World Wide Web could be described as major pillars of the new media category. Most often, when the term "new media" is mentioned, the first things that come to mind are the Internet and the World Wide Web, although other forms of digital, computer-facilitated communication media fall into this category.This work is specifically concerned with the print and new media. At this juncture, it is apposite to define and clearly explain what the new or social media entail, before identifying the major feature that distinguish betweenthe new media and traditional media.

\section{The New or Social Media}

Different terms such as "social media," new media," "online media," "web media," "digital media," "alternative media,"and "ICTs" have been used by researchers to describe the new technologies that complement and complicate the process of information gathering and dissemination. Auwal (2015a, p. 29) writes that, "these terms are used interchangeably to describe the new technologies in the communication industry. They are used to describe the digital and computerized communication technologies." Like other concepts in mass communication, the new media has no straight-jacketed definition. Nwabueze (2009, p. 146) affirms that, "it is still difficult to accurately state what comprises the new media. What exists is an attempt by various scholars to provide a working definition of what could be categorisedas the new media."Auwal (2015b, p. 29) defines new media as the "digital and computerized communication technologies such as blogs, podcasts, social networks, wikis, micro-blogs and message boards that can be used by the general public for interaction across distances." The author adds that "new media are products of globalization and scientific innovations which stem from the expansion of information and communication technologies."Nwabueze (2009) sees new media as products of the on-going information technology revolution which have separated the old communication technologies, basically those used prior to the advent of computer (land-line telephone, electronic news gathering camera, analogue radio and television, video text, wireless intercom system, etcetera) from the new communication technologies (computer, Direct Broadcast Satellite (DBS), digital radio and television systems, the Internet and World Wide Web, GSM phones, and so on). Today, the Internet and World Wide Web constitute major components of the new media. New media specifically refers to web facilitated communication channels which have redefined journalistic information sharing and dissemination with a more interactive senderreceiver relationship in a mass communication 
environment. "New media are seen generally to include all online creations - blogs, feeds, Google books, podcasts, vidcasts, online video (YouTube, blimps TV, etc), social network sites, search engines, affiliate programmes, online games, virtual trade shows, online communities, ebooks, kiosks, to mention a few" (Sponder, cited in Nwabueze, 2009).

New media can be described as a group of Internet-based applications that build on the ideological and technological foundations of the World Wide Web (WWW) that allows the creation and exchange of user-generated contents (Auwal, 2015b, p. 29). Asemah (2011a) explains that, new media is a broad term that emerged in the later part of the twentieth century to encompass the amalgamation of traditional media such as film, images, music, spoken and written words, with the interactive power of computer and communications technology, computer-enabled consumer devices and most importantly, the Internet. New media holds a possibility of on-demand access to content anytime, anywhere, on any digital device, as well as, interactive user feedback, creative participation and community formation around the media content. According to Asemah, new media are a disparate set of communication technologies that share certain features apart from being new, made possible by digitalization and being widely available for personal use as a communication device. The new media are not only or even mainly concerned with the production and distribution of messages, but at least, mainly concerned with processing, exchange and storage.

Hanson (2005) cited in Nwabueze (2009) notes that these (new media) are often referred to as "dot-coms." Most significant are the independent sites zines, weblogs, webcams, and gossip pages - that are operated by anyone who wants to be a publisher and has a website.According to a definition cited in Idiong (2012, p. 3), "the term new media is construed broadly to encompass all the digital, computerized, or networked information and communication technologies that have emerged since the later part of the twentieth century." Idiong explains further that, within this range of technologies are such innovations as the Internet, individual websites and blogs, computer games, mobile telephony, and even small or digital media such as computer discs with read-only memory (CD-ROMs), and digital versatile discs (DVDs). The author argues that, "this definition of new media does not include television, films, magazines, books or any paper-based publications - unless they contain technologies that enable digital interactivity, which is one of the cardinal characteristics of new media." According to Nafada (2012, p. 20), social media is an "online community" with avenues for 
social and business interactions among people who share similar interests. According to him, “social networking dates back to 1997 when 'sixdegrees.cm' came on board. Since then, the number of such websites has increased just as their interests have varied. Today, social network sites have become a global phenomenon and seem to be getting more attractive by the day."

Nwabueze (2009) explains that the concept of Information and Communication Technologies (ICTs) refers to technological developments that form the base of an improved communication process. They have been defined as electronic gadgets and a gamut of sophisticated technologies which facilities easy and meaningful communication in the modern age. They are a variety of continually improving technological breakthroughs which have diminished the initial barriers in communication and created an information superhighway which has largely contributed in shrinking the world into a "global village." These ICTs include the computer, satellite, and the Internet constitute the major pillars of ICT-driven communication activities woven around these technologies.

ICTs refer basically to the advanced technologies used in mass media operations. They also refer to the different technologies used in the production, storage and transmission of information. ICTs are rooted in the use of computer and computer related technologies such as electronics, satellite technologies, digitalised media equipment and the GSM (Nweke, 2011 in Ufuophu-biri and Shoki, 2008). Over the years, new media technologies have revolutionized almost all facets of human endeavours in the contemporary society.

\section{Distinction between the Traditional (Conventional) and the New or Social Media}

Social media are read-write web, where the online audience moves beyond passive viewing of web content to actually contributing to the content. One thing that is common in most definitions of social media is the point that it is based on user-generated participation. The opportunity to enjoy user-to-user interaction distinguishes social media from the traditional media which is characterized by top-down news dissemination arrangement.Another attribute of the social media which distinguish them from the traditional media is the choice it accords to its users. Choice enables people to access the information they like to learn about through the social media, eliminating the gatekeeper role of traditional media. On one hand, the choice offered by social media reduces the shared experience that viewers of particular traditional 
medium usually have.The new media create a network of individuals with like interests and similar preferences (Auwal, 2015a).

According to Baran (2002), the Internet is different from the traditional media. Rather than changing the relationship between audiences and industries, the Internet changes the definition of the different components of the process and as a result, changes their relationship. On the Internet, a single individual can communicate with as large an audience as can the giant, multinational corporation that produces a network television program. The main features which distinguish new or social media from the old or traditional media, as McQuail (2006) cited in Nwabueze (2009, p. 147) has pointed out, include their "interconnectedness," their "accessibility to individual users as senders and/or receivers," their "interactivity,"their "multiplicity of use and open ended character," their "ubiquity" and "delocatedness." Idiong (2012, p. 4-5) makes the point that, all technologies categorised as new media necessarily possess certain qualities that distinguish them from their predecessors, the so-called "old media." He itemizes the characteristics of the new media to include "digitality," "interactivity," "virtuality" and "hypertextuality."

In a nutshell, these explanations clearly point at the fact that the new media are "multipurpose" and "multi-featured" channels which combine most of the feature and characteristics of the traditional media, such as audio, video and textual elements. The absence of gatekeepers in the new media platforms is another feature that distinguishesthem from the traditional media. Nafada and Gudaku (2013, p. 14-15) vividly explain that, "the versatile nature of the Internet gave birth to what is today considered the 'social media,' a phrase being tossed around these days, that is difficult to define." But suffice to say that it is any media channel that does not just give you information, but interacts with you while giving you that information. One of the distinctive hallmarks of the conventional media is gate-keeping. The authors note further that:

By this, the content of the conventional media is usually made to undergo internal and external scrutiny and control in terms of editing to ensure that ethics and professionalism are religiously adhered to. Thus, what comes from the conventional media is not the product of one's pigment of imagination that is simply unverifiable, but "content baked in the containers of ethic and professionalism.'However, the concept of gate-keeping is completely absent 
when it comes to the social media. No one subjects whatever comesfrom the social media to any form of scrutiny. Hence what goes on in the social media could be the highest form of sensationalism, which the code of media ethics abhors. What calls for questioning is how easily people give in to sensationalism. The issues presented could even be from the figment of someone's imagination and therefore, misleading and smack of mischief. Therefore such could sell and indeed sell well, with amazing patronage from the unsuspecting public. Instead of serving the functions of information, the social media often turns out to serve the function of misinformation. To this wise, we can say that "social media new is not news."The difference is that the conventional media can be linked to one-way street where you can read a newspaper or listen to a report on television, but you have very limited ability to give your thoughts on the matter. In addition, social media is Internet based cross exchange of ideas and information that exists without gate-keepers and the concept is as good as the whims and caprices of the sender. Little ethics of the journalism profession is adhered to. Social media networks have been found to, oftentimes, favourmisinformation and sensationalism. Issues that would normally be verified in the conventional media go unchecked and unedited. More often than not, social media reports are subjective, misleading and smack of mischief.

The points made by Nafada and Gudaku clearly explain the importance of gate-keeping in journalism. This fact is justifiable because editing of news and other content reduces the amount of errors and unprofessional aspects in the information and messages disseminated to audience through the media. This important element of journalistic writings and practicesis completely absent in the new media, which is one of the distinguishing factors.

Another factor or feature which distinguishes the social media from the conventional media is timeliness. The speed at which online media disseminate information completely differs from that of the mainstream media. This could be in terms of immediacy or the area of coverage and reach of the message.Through the web media, communicators in Nigeria, for example can disseminate information to receivers in far-away London. These receivers are likely to get the message at the same time with their counterparts in Nigeria, Liberia and other parts of the 
world, respectively. Nafada and Gudaku (2013, p. 16) pinpoint that, "timelinessis another distinct mark of social media. Because it is timely, it has an undeniable advantage over conventional media." It is a known fact that, the world over,facebook, twitter and other social media platforms are operating with the philosophy "I hear first." The authors argue that "the social media will continue to take advantage of this reality for now because in news, ensuring that your news is timely is of utmost importance." New media platforms have the feature of immediacy, which the broadcast media also have. Stovall (2005) cited in Nwabueze (2009) avers that:

The web media offer an immediacy that broadcast media cannot match in four important ways; variety: they offer multi-faceted breaking news stories involving variety of people, places and activities, including textual, video and audio versions of a news break; expansion: they have the capacity to contain more information on a breaking news story than the broadcast media;depth: this refers to more details of a news break, though related to capacity. Here the depth story has,the chance of being edited before it is posted to the website or after the audienceshave seen it. The broadcast media do not often have opportunity to edit breaking news; and context: this refers to ability to provide a background summary of a news break either in textual, audio or video form while the story is on.

In fact, there are many other features and factors that distinguish the new media from the traditional media.

\section{New Media and the Survival of Traditional Media with focus on Newspapers and Magazine}

The advent of new mediatechnologies complement the operation of print media such that the management, production and distribution processes of newspapers and magazines have been mademuch easier. On the other hand, these technologies have complicated the activities and operations of the print media by posing great challenges to their survival in terms of reaching the audience with current news and information, and to a large extent, causeserious reduction in the revenue generated from advertising. New media technologies also pose great threat to ethical values and professionalism in the practice ofjournalism. This is to say that the impacts 
of these new technologies on the operation and survival of newspapers and magazines are both positive and negative. Garrison (1996) cited in Salman et al. (2011, p. 7) sees the arrival of New Communication Technology as bringing with it "a set of opportunities and challenges for traditional media professions such as journalism.”Uja (2013, p. 8) buttresses this point, stating that "the effort required in the production of newspapers and magazines have continued to progressively diminish in the course of the century due to increasing technology."'The author explains further that:

The emergence of the Information and Communication Technologies (ICTs) has not only aided the speed of information distribution but its offshoot - the social media, has taken on a very serious position in the field of mass communication.Hence, newspaper is facing serious competition and challenges. This is also due to the pervasive nature and innovations in ways of gathering, processing and dissemination of information by the new media. However, newspapers and magazines still play a very important role as means of communication in spite of all the threats from the new media, but their remaining a force depends on how they adapt to changes in order to fit into a changing media landscape.

According to Ufuophu-biri and Shoki (2008, p. 197), "the introduction of Information and Communication Technologies (ICTs) has made newspaper publishing easier and more effective. ICTs play pivotal role in mass media operations generally and in newspaper publishing, particularly." Nwabueze (2009, p. 145) stresses the point that "technological advancement has expanded the frontiers of communication and information dissemination in contemporary society." Nwabueze (2011) asserts that newspapers, magazines or book publishing, like every other activity, is presently defined by technological advancements of various types in the modern society. From the procurement of contents to printing process, the journey of a publication from raw to audience-consumable state has been made relatively less rigorous, less time consuming and less frustrating by digital encounters at one point or the other.Idemili and Sambe (2007) explain that, Nigerian journalism has undergone enormous positive change especially in the new millennium as a result of the introduction of Information and Communication Technologies. ICTs have propelled all forms of news media to break away 
from the established norms. This has strengthen the Nigerian mass media and made them more professional and effective. Computerization of all mass media organizations in Nigeria has made newspaper publishing easier, faster and cheaper. The computerization of mass media operation makes the whole operations less cumbersome, faster and error-proof.It will be wrong to conclude that the path in which these evolving technologies will follow is certain. These innovations (new media) have challenged a great number of newspaper and magazine establishments to develop website and online platforms where they can publish news, so as to be in line with the changing face of journalism in the contemporary society. In a similar note, Rabiu (2013, p. 318) avers that, "the Internet is rapidly evolving as a mass medium and the path that it will follow is still uncertain. But it is clear that it will incorporate a range of players." In the same vein, Salman et al. (2011, p. 3) comment that, "the long-term picture of new media or mass media information flows is not easy to predict."

It is also important to take into cognisance, the fact that the evolution of new technologies in the media or communication industry does not necessarily mean that the old platforms or channels are abandoned, overshadowed or completely erased from the media landscape by the new platforms. As Talabi (2011, p. 15) rightly describe, "no new medium can send an old one to oblivion, it will be an extension of the old medium." Salman et al. (2011, p. 2) support Talabi's assertion when they remark that "the presence of the Internet will not replace newspapers, just as radio did not replace newspapers and television." Daud (2008) cited in Salman et al. (2011) buttresses this fact in relation to the Malaysian media when he writes that, mainstream newspapers in Malaysia have gone through several stages of uncertainty and fear toward the end of 1997. This began with the emergence of online newspapers and websites which formed part of the new media and were made possible by the Internet. In the initial stage, the emergence of new media made conventional media owners worry about losing their influence and consequently, their profitability. The fear was not only that the new media were fast, colourful and borderless, but also that they affect the mind and psychology of readers who opt for alternative media. Salman et al (2011, p. 6-7) also state that:

Despite all these developments, newspapers both in the United States and Malaysia will not cease to operate. In the West itself, when television was introduced, there was an outcry that radio will die off. But until today radio still exists, continues to improve and is growing on a massive scale. Thepresence of 
online newspapers did not destroy the print newspaper. They are reinforcing each other. We argue that the presence of the Internet will not replace newspaper. Radio did not replace newspaper, and neither did television replace radio. The form of newspaper may change, but not the newspaper per se. The layout may change, but the content will still be in the form of news. Even if there is a drop in circulation, it is perhaps due to the youngsters shunning the mainstream or conventional media.

To marshal these points properly, it will be germane toidentify the areas in which new media technologies have affected the operations of conventional media in positive and negative ways for discussions.

\section{New Media Technologies improve (facilitate) Newsgathering and Dissemination Processes}

In modern era, there is hardly any journalist or media organization - print and broadcast, that do not make use of digital and computerized technologies (equipment or gadgets) in carrying out their daily activities of newsgathering, processing and dissemination. Uja (2013) observes that, new media technologies facilitate quick news gathering and filling. The array of gadgets today makes it much easier for journalists and reporters to put together their stories and file same to their editor from any location. The Internet, computer, I-pad and android phones have made all these possible such that editors more or less receive stories as they unfold. Nwabueze (2011) observes that Information and Communication Technologies (ICTs) have improved news gathering and processing, including production and management of newspapers and magazines. These are technologies that have generally improved sharing of ideas in modern society. They include such facilities as computer, the Internet, satellite technology, cable network and digital broadcast facilities, among others. Journalists gather stories from any part of the world and either fax or send them by e-mail to their editors in the head office. An average newspaper or magazine establishment in Nigeria has computerized its operations such that individual reporters in the field most of whom own laptop computer,have direct link with the editorial crew in the office via the Internet.

The new media is increasingly taking centre stage as the main tool for research, news production and distribution. Journalists, editors and news production staff in the media industry 
now use the Internet to deliver news in its various formats - audio, text, graphics, and video electronically or via bits and bytes, as opposed to atoms, or hard copy (Negroponte, 1995). New media technologies have made the worldsmaller for journalists to explore. Salman et al. (2011, p. 7) state that, "journalists, especially when writing for magazines, can gather news via the Internet and do their fact-checking or inquiries into facts and figures or background historical information directly from their homes or offices."

As the Internet changes the face of communication, journalists are beginning to have new ways of packaging and disseminating news to the public. Technologies have made it easier for journalists to conduct researches on various subject matters to complement their reports. As Nwabueze (2011) points out, the Internet is a major development that has facilitated editorial work in crucial ways. Journalists browse the Internet for facts used to back up stories, to develop themselves and other purposes. The advent of computer has greatly eased reportorial activities. Many journalists move about with their laptops and write stories even from venues of press conferences. Such stories are sent directly to the editor via e-mails. Newspapers now engage in 'breaking news' reporting just as the broadcast media. This is done in the online edition, a development made possible by the World Wide Web (WWW). Before the advent of World Wide Web, newspapers could not update what had already been published in the morning or evening edition (where a newspaper has two daily editions). But this has been changed with the advent of World Wide Web.

The advent of new technologies has intensified competition in the communication industry. In the print media industry, for example, virtually all newspapers and magazines have been made to establish website and other platforms for the dissemination of information online. As Abdulraheem, Adisa and La'aro (2012, p. 6) corroborate, "virtually all Nigerian newspapers have been adapting themselves to this new media age. The traditional medium for publishing content is paper, and now newspapers have tried certain new medium such as online newspaper edition and mobile phone newspapers. As at today, 60 Nigerian newspapers are online.”

\section{New Media Technologies affect the Patronage, Readership and Circulation of Newspapers and Magazines}

The advent of new media technologies greatly affects the level of patronage, readership and circulation of printed newspapers and magazines.The coming of online media has to some 
extent, affect readership habits, as consumers turn to the Internet for free news and information. The circulation of printed newspapers and magazines has also been affected by these technologies.In the modern era, the ratio of readers whopatronize online publications is greater than those who buy and read printed newspapers and magazines. Abdulraheem, Adisa and La'aro (2012, p. 3) explain that the Internet brought this social state. Most of the newly empowered middle class have access to the Internet and seriously have developed a mind set. The authors raised a question which is believed to be the mind set of many people in the modern age: "why should I buy a newspaper for information when the same is available on my blackberry free of charge? Moreover, the Internet gives me access to different sources of the same information - all for free." Murdoch, cited in Abdulraheem, Adisa and La'aro (2012, p. 6) captures this point more succinctly when he comments that, "the dynamic revolution taking place in the news industry today revolves around the fact that technology-savvy young people are becoming increasingly likely to turn to the web as their news medium of choice."

This trend has made publishers to reduce the number of newspapers or magazines they produce on daily, weekly or monthly basis and concentrate more on their websites and other social media platforms for dissemination of news and views. Nafada and Gudaku (2013) argue that, to this regard, radio, television, newspapers and magazines have joined the trial with online publications, facebook and twitter accounts all in an attempt to present news to their audience in real-time as well as foster intimate and personal relationship with the audience.Also, e-news has become the trend. Profitability of the conventional media is greatly affected as more people read and access news online than people who actually purchase newspapers and magazines. Such online publications have been forced to compete with other platforms(social media)in terms of immediacy.

According to Garrison (2001) cited in Salman et al (2011, p. 2), "the advent of new media has posed a challenge to conventional media. The new media has also affected the way newspapers get and circulate their news. Their effect, for example, is felt on the circulation of print newspapers, especially in the United States."The author explains that, "since 1999, almost 90\% of daily newspapers in the US have been actively using online technologies to search for articles and most of them also create their own news websites to reach new markets." Salman et al, further explain this scenario, citing the Malaysian press thus: "it is, therefore, not 
surprising that many Malaysians have turned to alternative media for new sources of information, news and views. However, in Malaysia, the effect of the new media on conventional media is still manageable."

Fordham (2010) explains that, digital media platforms have greatly expanded the news industry so that traditional newspapers are competing with online news aggregators for news articles, readers, and advertising revenue. News aggregators gain their competitive advantage against traditional newspapers, in part, by using newspapers' copyrighted content. If the newspaper industry is to effectively compete in the digital marketplace with news aggregators, it is imperative that it use copyright law to protect its commercially valuable news content.Over the years, there has been an intense argument among commentators and critics on the causes of the decline in patronage, readership and circulation of newspapers and magazines in Nigeria and other countries of the world. Ekeng (2010) cited in Abdulraheem, Adisa and La'aro (2012) observes that,circulation decline is a global phenomenon as the newspaper industry in America, Europe and even Asia is also affected. This, the author said is primarily due to the impact of Internet, which guarantees quick news for free. Topping the list of all the causes is the crashing local economy, which has greatly reduced the purchasing power of most Nigerians. However, the impact was between 2003 and 2012, when sales figure dropped from 570,000 units per day to less than 300,000 units, signifying about 50 percent drop.

\section{Reduction in the Revenue Generated from Advertising}

The advent of new media technologies caused serious reduction in the percentage of revenue generated from advertising, which is the major source of survival for newspaper and magazine publishing firms. This point is closely related to the reduction in level of patronage, readership and circulation of newspapers and magazines. Fordham (2010) rightly explain this when he notes that, the introduction of radio broadcasts in the 1920s and broadcast television in the 1950s caused the newspaper industry to face declines in circulation as consumers had access to alternate sources for news and advertisers started buying air time, rather than print advertising, to reach more consumers. Although radio and television diversified the media landscape, the newspaper industry was able to adapt to these changes and maintain its strong market position. The author explains further that: 
However, revenue from print advertising is rapidly decreasing as advertising has greatly migrated towards the Internet. In 2008, classified advertising declined $29.7 \%$ from 2007, which was a loss of $\$ 4.2$ billion for the newspaper industry. Print advertising also suffered with an overall decline of $17.7 \%$ from 2007 to 2008 , which was a loss of $\$ 7.5$ billion for the newspaper industry.In 2008 , even online advertising declined $1.8 \%$, a $\$ 3.1$ billion decrease from 2007.As of 2008, online advertising only accounts for approximately $10 \%$ of the newspaper industry's total advertising revenue. These statistics reveal the newspaper industry's financial troubles and show that the future of the newspaper industry will depend on the growth of its online market. In comparison to radio and television, the Internet has disrupted the newspaper industry's traditional business model in three important ways. First, the Internet is capable of freely distributing news and information at a zero variable cost unlike newspaper publishers that have to pay for print and distribution costs. Second, the Internet has greatly expanded the field of competition in news delivery due to low entry costs, as anyone with a computer and an Internet connection can distribute news. Third, the Internet has changed consumer habits so that individual buyers and sellers can directly connect on the Internet using free classified sites like Craigslist and Monster or low-cost sites like eBay. For the remaining advertisers, traditional newspapers now have to compete with new media entrants for advertising dollars to sustain their business. Thus, the Internet has caused a dramatic shift in the way news is delivered and supported by advertising. As a result, the newspaper industry will need to make significant changes to its traditional business model as market demand has moved away from print to online news consumption. To survive, newspapers will have to change their strategy.

Advertising revenues are tumbling due to the severe economic downturn, while readership habits are changing as consumers turn to the Internet for free news and information. Some major newspaper chains are burdened by heavy debt loads. As in the past, major newspapers have declared bankruptcy as several big city papers shut down, lay off reporters and editors, impose pay reductions, cut the size of the physical newspaper, or turn to web-only publication (Kirchhoff, 2009 in Salman et al., 2011). Newspapers, especially in the West and the US in 
particular, have lost the lion's share of classified advertisement to the Internet. The situation worsened when a depressed economy forced more readers to cancel their newspaper subscriptions, and business firms to cut their advertising budget as part of the overall costcutting measurements. As a result, closures of newspapers, bankruptcy,job cuts and salary cuts are widespread (Mahmud, 2009 cited in Salman et al., 2011). Gapsiso (2008, p. 186) avers that, "technology has changed both ally and enemy to newspapers. Television forced newspaper to change the way they did business and served their readers. Now online computer networks pose the greatest challenge to this medium, online job hunting and autosales services are already cutting into classified advertising profits of newspapers." The author explains further that, as a result of these technologies, traditional newspaper is reinventing itself by converging with these very same technologies. In fact, the newspaper industry recognizes that it must accept economic loses while it is building online readers trust, acceptance, and above all regular and frequent use.

Today, many advertisers prefer usingsocial media platforms such as facebook, twitter, youtube, google, among others to advertise their products and services because of the peculiar assumption and belief that theInternet has wider reach than printed newspapers and magazines. For this reason, a considerable number of publications (newspapers and magazines) have been forced to migrate or create online platforms where they provide information and advertisements on products and services. Thishas caused serious drop in the revenue generated through advertising and promotion by the print media, as advertisers now have the leverage of placing advertisements on social media platforms at low or no cost.

\section{Improvement in Quality and Reduction in the Cost of Newspapers and Magazines}

\section{Production}

With the introduction of computer and the Internet, the production process of newspapers and magazines has been revolutionized and made much easier, resulting to improvement in the quality of publications. Gapsiso (2008) points out that, the newspaper industry is witnessing a remarkable revolution in relation to the role of ICTs in the production process. As a result of these, there is improvement in design, layout and quality. This development has also speed up the production process. Sambe (2014a, p. 107-117) writes that, "new communication technologies have made both reporting and other processes of publication quite simple. Though many news organs now employ these technologies greatly, the usage is still hampered by poor 
economy and death of facilities in rural areas." The author explains further that, the publishing industry has continued to experience changes occasioned by advances in information and communication technologies in the areas of copy writing, reporting, editing, page making, filming, the industry has witnessed a revolution. Desktop publishing (DTP) has redefined publishing. The advent of DTP brought life, vigor and fun into publishing. It has simplified publishing which is hitherto inflexible. The old system was in fact tedious. Sambe asserts that, "the advent of electronics in the 1970s radically redefines the processing (editing) of copy. By 1970s many print organs in the west - especially the US - were employing the merging technology - Video Display Terminals (VDTs) in processing copy. Nwabueze(2011) is in agreement with Sambe's explanations on Desktop Publishing (DTP) when he observes that, desktop publishing facilities have made newspapers and magazines publishing less laborious and requiring fewer hands. Desktop publishing is computer facilitated process that permits the typesetting of manuscripts or stories, editing, page planning and make-up, proofreading, scanning of photographs and illustrations into a page, and other pre-press activities without having to pass through the rigoursassociated with the old system of newspaper and magazine publishing prior to the advent of computer technology. For instance, in photo editing, meter rule and mathematical methods of cropping are no longer common. Photo editing or photocropping is now done on the computer by simple adjustment of the photograph in the pagemaker programme. Desktop publishing is made possible by new technologies. Newspapers and magazines have websites where online edition of the publication is published. Bittner (1989, p. 995) avers that, "the integration of high resolution graphics, sophisticated software and quality resolution laser printers opened up the field of desktop publishing."Bittner explains further that, the concept of electronically composed pages is not new and has been in use in the newspaper industry for a number of years, but the systems were more industrial than personal. Along with increased simplicity, a decrease in price as well as the size of the hardware permits many people to become involved in publishing enterprises that in the past would have been too expensive. For example, one individual can write, compose, and print out an illustrated fullpage master, whereas in the past it would have taken different people to write, illustrate, and paste up the page. The saving of time alone has made many publishers convert to desktop publishing systems. 
Before now, the processes involved in the production of newspapers and magazines typesetting, filming, plate-making and printing, are tedious and time consuming.Today, the processes have been made easier with the introduction of new printing technologies that eliminate the use of plates. First, typesetting of stories and articles to be published was doneusing typewriters, which takes long time to be accomplished.Newmedia technologies have also lessen the number of people required in the production process. As Nwabueze (2011) points out, the process of typesetting is now done through what is called phototypesetting -an electronic process that replaced the linotype process which used to cast lines of type with the assistance of a keyboard operator. Phototypesetting makes the process faster and easier. The dummy sheetsare reflected and by an operator on a rough page prototype. This is printed for proofreading and adjustments, such that if need be, the entire page layout could be altered within minutes. This way, ICTs have introduced flexibility, creativity and speed in page planning, layout and design. According to Nwabueze, today, the advancements have eased the typesetting process, introducing a phototypesetting process whereby the dummy is first transferred to the page layout section of a newspaper or magazine, the instructions on the dummy are transferred into a page which is usually printed out and crosschecked by an editorial staff or any other staff delegated with that responsibility to ensure that the layout instructions were followed and embarrassing errors pointed out. The copy editor, news editor, sub editor, night editor, duty editor (as the case may be) could undertake the task of crosschecking the copies.

Newspapers and magazines were printed in black and whitecolours, using the old methods of filming and platting before production. According to Nwabueze (2011, p. 83), "a plate is an aluminum sheet with light sensitive coating onto which the negative image of each page is transferred. This process of plate-making is sometimes called platting. It is the form which the newspaper or magazine will be printed in the printing press." The author explains these processes extensively in the following words:

Image transference (filming) consist the use of laser beams and other technological apparatus to transfer the computer form of various pages of the publication onto thin plastic, light sensitive, floppy sheets called film. These films are developed in a processor after which photographs scanned into another computer terminal are inserted into the page layout. Pages that would 
be printed together are arranged and taped together on a device called "tripper." This tripper is placed on a light sensitive film and the image of each page is burned onto the film. Another device called "laser reader" scans the pages and transfers them to a laser writer which also scans and makes negative image of the page, with the text (written materials) appearing white while the blank spaces appear black. The filming process was formerlydone with a device called the "compugraphic machine."This was prior to the advent of digitalized laser beam devices which are in use today. The compugraphers were in charge of the filming process. Technology has made filming a lot easier in modern times. Formost newspapers, the pages are burned in twos on each plate while for magazines, the pages are burned in fours on each plate (depending on the size i.e. A2 or A3 size). First, the films (negatives) are placed on a lighted box,then the plates are placed on the image of the pages (negatives) after which the light box is switched on. Ultraviolet light then develops the image of the pages onto the aluminum plate. This process is done repeatedly for all the plates to be used for the production of each edition. Each plate is bent at the edges (so that it will fit into the printing machine) after which they are fixed onto plate cylinders for printing to commence. Plating and printing are continually witnessing technological improvements. Today, the Direct Imaging (D.I) printing process has become the vogue. This is the process that consists of printing pages of a newspaper, magazine or book directly from the computer i.e.the process eliminates filming and plating by sending the pages in the computer direct to the printing press (machine). This is a major technological breakthrough in publishing.

These assertions indicate that printing, which is thefinal stage in the production of newspapers and magazines, was relatively tedious and time consuming before the advent of new media technologies. With the technological advancements in the industry, an individual can singlehandedly undertake different activities or tasks that require more hands, using the computer and new printing machines.

\section{New Media Influence the Management Process of Newspapers and Magazines}

New media technologies have eased the task of managing the newspaper and magazine establishments. According to Uja (2013), the effort required in the production and management 
processes of newspapers and magazines hascontinued to progressively diminish in the course of the century due to increasing technology. The emergence of Information and Communication Technologies (ICTs) has not only aided the speed of information distribution but its offshoot - the social media, hastaken a very serious position in the field of mass communication. Nwabueze (2011, p. 96-98) argues that "new technologies are crucial in the growth and profitability of newspapers and magazines in modern society." He adds that "new technologies are used in managing the editorial and production (pre-press and press) activities. However, ICTs have positively influenced management of print media activities in other specific ways." New technologies facilitate communication in print media management process. Computer and Internet technologies play vital roles here.

\section{Conclusion and Recommendations}

From the foregoing discussions, it is evident that the advent of new media technologies posed great challengesto the survival of traditional media, especially the print media industry. These challenges are both positive and negative, as new technologies complement and complicate the reportorial role of journalists and the media in the contemporary society. "The challenges faced by conventional media, especially newspapers, has to do with the perfect storm of the global economic crisis, dwindling readership and adverting dollars, and the inability of newspapers to mobilize their online efforts" (Yap, 2009 in Salman et al, 2011, p. 4).Technological innovations have affected all facets of human endeavour. As Nwabueze (2011, p. 89) rightly asserts, "today, there is hardly any aspect of human activity that does not have an 'e' attached to it, as a result of the influence of ICTs on that activity. For instance, there is e-business, e-advertising, epublic relations, e-mails, e-medicine, and of course e-publishing." $\mathrm{He}$ adds that "in the print media, newspapers, magazines and books are today produced through a process largely facilitated by ICTs."

The future or survival of traditional media (newspapers and magazines) is dependent on their ability to adopttechnologiesand new ways of doing things into their operations and activities. Abdulraheem, Adisa and La'aro (2012, p. 2) argue that "unless the print media braced up to the challenges posed by the new media, it might go extinct in the nearest future." 


\section{References}

Abdulraheem, M., Adisa, R. M., \& La'aro, A. O. (2012). Information and Communication Technology Revolution and the Future of Print Media in Nigeria: Usage Across Age Groups. Advances in Management, 10(1). Ilorin: Department of Business Administration, University of Ilorin.

Asemah, E. S. (2011a). Mass Media in the Contemporary Society. Jos: Jos University Press Limited.

Asemah, E. S. (2011b). Principles and Practice of Mass Communication, Second Edition. Jos: Jos University Press Limited.

Auwal, A. M. (2015a). New Media and Education: Assessing Its Impacts on the Academic Performances of Nigerian Students. New Media and Mass Communication, 16(3). USA: International Institute for Science, Technology and Education (IISTE).

Auwal, A. M. (2015b). Issues in Nigerian Media: The Global Perspectives (Unpublished Manuscript). Keffi: Department of Mass Communication, Nasarawa State University, Keffi.

Baran, S. (2002). Introduction to Mass Communication: Media Literacy and Culture. New York: McGraw-Hill.

Bittner, J. R. (1989). Mass Communication: An Introduction (5 ${ }^{\text {th }}$ Ed.). New Jersey: PrenticeHall Inc.

Esimokha, G. (2011). Newspaper \& Magazine: Editing, Production and Marketing. Lagos: Great Achievers Communications.

Ezea, G. H, Ozibo, O., \& Hassan, A. M. (2013). The Internet, New Media and Approaches to Advertising Business in Nigeria. In D. Wilson (ed.). Communication and the New Media in Nigeria: Social Engagements, Political Development and Public Discourse. African Council for Communication Education (ACCE) Nigerian Chapter.

Fordham, K. (2010). Can Newspapers Be Saved? How Copyright Law Can Save Newspapers from the Challenges of New Media. Fordham Universit School of Law. Retrieved on May 13, 2014 from http://iplj.net/blog/archives/volumexx/book3.

Gapsiso, N. D. (2008). ICTs and the Future of Newspapers in Nigeria. In E. M. Mojaye, E. Arhagba, L. Oso, \& E. Soola (Eds.). Media, Dialogue, Peace Building and Reconciliation: Conference Proceedings. Ibadan: African Council for Communication Education (ACCE) Delta State Chapter. pp. 197-202. 
Idiong, N. S. (2012). New Media, New Challenges: Navigating the Changing

Topography of Nigerian Journalism. Journal of Multimedia Technology and

Communication Studies, Vol. 1. Keffi: Department of Mass Communication, Nasarawa State University.

Nafada, A., \& Gudaku, B. (2013). Impact of the Social Media on the Conventional Media. The Press, Issue Number Nineteen. Abuja: Nigerian Press Council (NPC).

Nwabueze, C. (2009). Reporting: Principles, Approaches and Special Beats. Owerri:

Topshelve Publishers.

Nwabueze, C. (2011). Magazine and Newspaper Management and Production: An Introductory Text. Owerri: Topshelve Publishers.

Rabiu, M. S. (2013). The World of News: Career Prospects in Journalism and Mass Communication. Ibadan: Stirling-Horden Publishers Limited.

Salman, A., et al. (2011). The Impact of New Media on Traditional Mainstream Mass Media. The Innovation Journal: The Public Sector Innovation Journal, 16(3), article 7.

Sambe, S. A. (2014a). A Guide to Newspaper Production. Makurdi: Samphill Communications Limited.

Sambe, S. A. (2014b). Magazine Production and Management. Makurdi: Samphill Communications Limited.

Talabi, F. O. (2011). “The Internet and Journalism Practice in Nigeria.”Global Journal of Human Social Science, 11(10), Version 1.0.

Ufuophu-Biri, E., \& Shoki, G. (2008). Role of Information and Communication Technologies in Newspaper Reportage of the Niger Delta: Study of the Vanguard Newspaper. In E. M. Mojaye, E. Arhagba, L. Oso, \& E. Soola (Eds.). Media, Dialogue, Peace Building and Reconciliation: Conference Proceedings. Ibadan: African Council for Communication Education (ACCE) Delta State Chapter. pp. 197202.

Uja, O. (2013a). Community Newspapers in the Era of the Social Media. The Press, Issue Number Nineteen. Abuja: Nigerian Press Council (NPC).

Uja, O. (2013b). Newspaper Management: Key to Survival in an Era of Social Media. The Press, Issue Number Nineteen. Abuja: Nigerian Press Council (NPC). 